\title{
RELAÇÃO ENTRE DEMANDA JUDICIAL E FORÇA DE TRABALHO NAS JUSTIÇAS ESTADUAIS NO BRASIL
}

\author{
RELATIONSHIP BETWEEN JUDICIAL DEMAND AND WORKFORCE IN STATE COURTS IN BRAZIL \\ RELACIÓN ENTRE DEMANDA JUDICIAL Y FUERZA DE TRABAJO EN LOS TRIBUNALES ESTADUALES EN BRASIL
}

\section{RESUMO}

A grande quantidade de processos peticionados - demanda judicial - e a incapacidade de resposta adequada a essa demanda é um dos principais problemas do Judiciário brasileiro e de boa parte dos judiciários de outros países. Embora os tribunais brasileiros tenham conseguido aumentar a capacidade produtiva nos últimos anos, a demanda crescente acaba gerando uma sensação de ineficiência e resultando no que ficou conhecido como "congestionamento dos tribunais". Diversos fatores estão relacionados ao congestionamento, e o presente estudo busca testar um desses fatores: a força de trabalho. 0 objetivo é descrever a relação entre a taxa de congestionamento de tribunais e a força de trabalho disponível. Os dados foram coletados na base Justiça em Números (CNJ), e referem-se à primeira instância das justiças estaduais no período de 2009 a 2016. Para analisar os dados, foram utilizadas técnicas de estatística descritiva e correlação linear. Os resultados do estudo apontam que a taxa de congestionamento está correlacionada positivamente com a força de trabalho absoluta nas justiças. No entanto, a correlação passa a ser negativa quando considerada a força de trabalho proporcional ao total de habitantes. Isso indica que a política de alocação de pessoal nas justiças estaduais brasileiras está desalinhada com a demanda judicial.

PALAVRAS-CHAVE: Administração da justiça, Justiça Estadual, demanda judicial, congestionamento de tribunais, força de trabalho.

Adalmir de Oliveira Gomes ${ }^{1}$

adalmirdeoliveira@gmail.com

ORCID: 0000-0001-9000-3296

Bernardo Oliveira Buta', 3

bernardo.buta@gmail.com

ORCID: 0000-0002-8936-3697

Rafael Rabelo Nunes ${ }^{1}$

rafaelrabelo@unb.br

ORCID: 0000-0002-1538-4276

${ }^{1}$ Universidade de Brasília, Departamento de Administração, Brasília, DF, Brasil

${ }^{2}$ Defensoria Pública-Geral da União, Brasília, DF, Brasil

${ }^{3}$ Fundação Getulio Vargas, Escola de Administração de Empresas de São Paulo, São Paulo, SP, Brasil

Submetido 26.11.2017. Aprovado 06.06.2019

Avaliado pelo processo de double blind review

DOI: http://dx.doi.org/10.12660/cgpc.v24n78.72978

Esta obra está submetida a uma licença Creative Commons 


\begin{abstract}
The large number of judicial cases - caseload - and the inability to appropriately respond to such caseload is one of the main problems of the Brazilian Judiciary, and of many judiciaries around the world. Although Brazilian courts have been able to increase production capacity in recent years, the growing demand generates a sense of inefficiency and results in what is known as 'court congestion". Several factors are related to congestion, and the present study seeks to test one of these factors: the work force. The objective is to describe the relationship between the rate of congestion of courts and the available work force. Data were collected on Justice in Numbers (CNJ) database and refer to state courts from 2009 to 2016. To analyze the data descriptive statistics and linear correlation techniques were used. Results indicate that congestion rate is positively correlated to the absolute workforce in justice. However, the correlation becomes negative when the workforce considered is proportional to the number of inhabitants. This indicates that the policy of personnel allocation in Brazilian state justice is misaligned with the caseload.
\end{abstract}

KEYWORDS: Court administration, State Court, caseload, congestion of courts, workforce.

\title{
RESUMEN
}

El gran número de casos judiciales -demanda judicial- y la incapacidad de responder adecuadamente a esa demanda es uno de los principales problemas del Poder Judicial Brasileño y de muchos sistemas judiciales en todo el mundo. Aunque los tribunales brasileños han podido aumentar la capacidad de producción en los últimos años, la creciente demanda genera una sensación de ineficiencia y da como resultado lo que se conoce como 'congestión de los tribunales.' Varios factores están relacionados con la congestión y el presente estudio busca probar uno de estos factores: la fuerza de trabajo. El objetivo es describir la relación entre la tasa de congestión de los tribunales y la fuerza de trabajo disponible. Los datos se recopilaron de la base de datos de Justicia en Números (CNJ) y se refieren a las justicias estatales del período de 2009 a 2016. Para analizar los datos se utilizaron las técnicas de estadística descriptiva y correlación lineal. Los resultados indican que la tasa de congestión se correlaciona positivamente con la fuerza laboral absoluta en los tribunales. Sin embargo, la correlación se vuelve negativa cuando la fuerza considerada de trabajo es proporcional a la cantidad de habitantes. Esto indica que la política de asignación de personal en la justicia estatal brasileña está desalineada con la demanda.

PALABRAS CLAVE: Administración de la justicia, Justicia Estatal, demanda judicial, congestión de tribunales, fuerza de trabajo.

\section{INTRODUÇÃO}

Um dos problemas centrais do Judiciário brasileiro é a enorme quantidade de processos judiciais em tramitação em todos os segmentos e instâncias judiciais. A grande quantidade de processos ajuizados e a incapacidade dos tribunais em responder adequadamente à demanda gera um fenômeno que ficou conhecido como "congestionamento judicial." O congestionamento é uma taxa utilizada pelo Conselho Nacional de Justiça (CNJ) e representa o percentual de processos ajuizados e aguardando julgamento em relação ao total de processos tramitados em determinado período.

Mesmo com melhoras nos indicadores de produtividade de tribunais brasileiros nos úl- timos anos, o relatório Justiça em Números (CNJ, 2017), mostra que o aumento constante da demanda judicial acaba agravando a situação, de modo que as altas taxas de congestionamento observadas ficam difíceis de serem superadas. O relatório Justiça em Números (CNJ, 2016) mostra que a maior taxa de congestionamento se encontra na primeira instância da Justiça Estadual, totalizando $75 \%$ de taxa de congestionamento bruta, relativa à totalidade dos processos; e $73 \%$ de taxa de congestionamento líquida, que desconsidera os processos suspensos, sobrestados ou em arquivo provisório. Em resumo, considerando todos os processos que tramitaram na Justiça Estadual em 2015, apenas $25 \%$ foram baixados.

O presente estudo trata do fenômeno do 
congestionamento de tribunais observado na primeira instância das justiças estaduais do Brasil. A taxa de congestionamento é um dos indicadores mais importantes do Judiciário, uma vez que mostra o impacto direto da ineficiência na gestão dos processos judiciais em tribunais. Diversos fatores estão relacionados ao congestionamento, como o acesso e a litigiosidade, os custos processuais, os recursos financeiros e tecnológicos disponíveis etc. O presente estudo busca testar um desses fatores: a força de trabalho disponível no tribunal. O objetivo do estudo é identificar a relação entre a demanda judicial, representada pela taxa de congestionamento e a carga de trabalho, e a força de trabalho disponível nas justiças estaduais no Brasil. A força de trabalho consiste na quantidade de juízes e servidores auxiliares.

Diversos estudos anteriores (Beenstock \& Haitovksy, 2004; Castro, 2011; Gomes, Guimaraes, \& Akutsu, 2016, 2017; Souza \& Schwengber, 2005) investigaram a relação entre força de trabalho e desempenho judicial, no entanto a relação entre congestionamento e força de trabalho praticamente não tem recebido atenção na literatura. Assim, a presente pesquisa busca suprir essa lacuna. Além disso, a pesquisa busca gerar informações que podem indicar se a política de alocação de juízes e servidores em tribunais e nas varas da Justiça Estadual está em conformidade com a demanda por serviços de justiça e com o próprio CNJ, cuja Resolução no 219/2016 determina que a quantidade total de servidores que auxiliam diretamente os juízes deve ser proporcional à quantidade média de processos distribuídos em cada unidade judicial.

DEMANDA JUDICIAL E CONGESTIONA-

\section{MENTO}

No Brasil, a Constituição de 1988 ampliou consideravelmente os direitos e garantias da população, o que repercutiu na quantidade de processos que são ajuizados no Judiciário. A tensão que resultou em razão das promessas trazidas pela Constituição de 88 e a sua não efetivação estaria entre os principais motivos da chamada crise do Poder Judiciário (Capellari, 2001). Apenas para ter uma noção do tamanho do problema, em 2016, existiam aproximadamente 80 milhões de processos pendentes em todo o Judiciário brasileiro. $\mathrm{O}$ Judiciário consegue julgar apenas 20 milhões de processos por ano, praticamente a mesma quantidade de novos processos que são ajuizados por ano e que, portanto, entram no sistema (CNJ, 2017).

O aumento da necessidade de solução de conflitos por parte da sociedade tem impactado o Judiciário de tal forma que os processos começam a acumular em prateleiras ou em bancos de dados, não sendo possível dar vazão suficiente para reduzir a carga de trabalho dos juízes. A essa situação narrada, os estudiosos têm dado o nome de congestionamento do Judiciário. No contexto judicial, a palavra tem sido utilizada de modo semelhante, mas para processos judiciais, e não veículos. Nesse sentido, congestionamento daria a ideia de "engarrafamento" de processos judiciais, remetendo à noção de acúmulo de processos. O congestionamento no Judiciário é problema há muito destacado e, por isso, presente em diversos estudos de alcance internacional. O Banco Mundial, em 1999, já trazia o congestionamento como um dos problemas mais frequentemente reclamados por usuários de judiciários de muitos países (Banco Mundial, 1999). 
A crescente judicialização de políticas públicas no Brasil tem contribuído para o aumento do congestionamento de tribunais. Se, por um lado, a judicialização da política representa um movimento expansivo dos diretos na sociedade civil (Vianna, 2013), por outro, indica uma desconfiança em relação às tradicionais instituições representativas (Filgueiras \& Marona, 2012), mostrando uma falha na entrega de serviços públicos essenciais, como nos casos da judicialização da saúde e da educação, e obrigando, assim, o cidadão a buscar seus direitos diretamente no Judiciário.

Outra abordagem ao problema do congestionamento de tribunais consiste no combate à litigiosidade, evitando que os litígios se tornem judicializados por meio dos chamados mecanismos alternativos de resolução de litígios, como a conciliação, a mediação e a arbitragem. O CNJ, por meio da Resolução n 198/2014, considera, como cenário desejado para os próximos anos, uma Justiça brasileira mais acessível e menos congestionada, e uma das estratégias para isso são os mecanismos alternativos de resolução de conflitos (CNJ, 2017). A conciliação e a mediação já são oferecidas no Brasil por várias organizações judiciais e extrajudiciais, e muitos desses serviços são on-line, ou seja, prestados totalmente ou parcialmente pela internet, fenômeno conhecido na literatura como on-line dispute resolution (ODR).

\section{Taxa de congestionamento}

Com a finalidade de mensurar alguns dos problemas relacionados ao congestionamento e acúmulo de processos no Judiciá- rio, foram criados diversos indicadores, entre eles a chamada "taxa de congestionamento". Esse termo não tem significado matemático uniforme. No clássico texto do Banco Mundial sobre o tema, a chamada "congestion rate" é medida por meio da divisão entre o caseload, ou seja, a quantidade de processos pendentes e a quantidade de processos resolvidos em um tribunal (Banco Mundial, 1999).

Para o Centro de Estudios de Justicia de las Américas (CEJA), a "tasa de congestión" é medida pelo quociente entre o número de casos registrados no ano mais os pendentes no início do período, dividido pelo número de casos resolvidos durante o ano (Pastor, 2003). O Conselho Nacional de Justiça (CNJ), por meio da Resolução $n^{\circ} 219 / 2016$, entende que a taxa de congestionamento é obtida a partir do percentual de processos pendentes em relação ao total de processos que tramitaram no ano (processos baixados mais processos pendentes). A partir de 2015, o relatório Justiça em Números passou a divulgar também a chamada "taxa de congestionamento líquida", obtida com a exclusão dos processos sobrestados, suspensos ou aguardando em arquivo provisório (CNJ, 2015).

Embora a taxa de congestionamento e outros termos correlatos sejam utilizados para medir o aumento do acervo de processos no Judiciário, outros indicadores também são empregados com objetivos próximos. $O$ Banco Mundial faz referência a outros indicadores, como a clearance rate, que é medida a partir da divisão entre casos resolvidos e casos arquivados; caseload per judge, que leva em conta o número de casos arquivados, resolvidos e pendentes por juiz; e time 
RELAÇÃO ENTRE DEMANDA JUDICIAL E FORÇA DE TRABALHO NAS JUSTIÇAS ESTADUAIS NO BRASIL

to resolve a case, que dispõe sobre o tempo médio necessário para solução da demanda (Banco Mundial, 1999).

\section{Congestionamento e força de trabalho}

Diversas estratégias e inovações têm sido adotadas pelo Judiciário brasileiro ao longo das duas últimas décadas para enfrentar o problema do congestionamento da justiça, como a criação dos juizados especiais, a instituição de mecanismos alternativos de resolução de litígios, o investimento pesado em tecnologias da informação e comunicação (Gomes, Alves, \& Silva, 2018), a institucionalização da sistemática da demanda repetitiva, a realização de mutirões no julgamento de processos, entre outras. O presente estudo trata da gestão da força de trabalho.

A relação entre a força de trabalho disponível e o congestionamento de tribunais praticamente não tem recebido atenção por parte de pesquisadores. $O$ interesse maior tem sido pela relação entre força de trabaIho e o desempenho judicial. Nesse caso, os resultados são variados e, muitas vezes, controversos. Alguns estudos (Beenstock \& Haitovksy, 2004; Castro, 2011; Gomes et al., 2016; Souza \& Schwengber, 2005) indicam que aumentar o número de juízes em uma unidade pode aumentar a produção total da unidade. No entanto, o efeito sobre a produtividade pode ser nulo, ou mesmo reduzir a produção individual dos juízes e, consequentemente, a produtividade da unidade.

Dimitrova-Grajzl, Grajzl, Sustersic e Zajc (2010), por exemplo, estudaram a importância da força de trabalho na produtividade de tribunais na Eslovênia. $O$ estudo apresenta como resultado, entre outras coisas, o fato de que a força de trabalho não influencia significativamente a resolução de processos nos tribunais investigados. $O$ estudo de Beenstock e Haitovsky (2004) indicou que a quantidade de juízes em unidades judiciais não afetava a produtividade da unidade, uma vez que o aumento na quantidade de juízes não gerava aumento significativo na produção judicial individual (Beenstock \& Haitovsky, 2004). Gomes e Freitas (2017), ao estudarem a Justiça Federal brasileira, concluíram que existe um mecanismo que gera uma redução do ritmo de trabalho em varas quando a quantidade de juízes alocados é alta. No mesmo sentido, os estudos de Aragão (1997) e Yeung e Azevedo (2012) mostraram que apenas aumentar a quantidade de juízes não necessariamente garante aumento na produção judicial.

O estudo de Castro (2011), realizado nas varas da primeira instância da Justiça Estadual no Brasil, indicou que aumentar a quantidade de juízes em uma vara de justiça pode até mesmo representar uma redução na produção judicial da vara. Segundo Castro (2001), isso ocorre porque o aumento na força de trabalho gera uma diminuição na pressão sobre cada juiz, tendo em vista a redução da carga de trabalho individual. Assim, contratar novos juízes e servidores pode não ser suficiente para aumentar a eficiência do tribunal. Castro (2011) mostra também que a produção de um juiz é positivamente correlacionada com sua carga de trabalho, e conclui dizendo que "o sistema [judicial] possui mecanismos auto reguladores" da produção, de modo que, "quando a carga de processos pendentes aumenta em uma unidade, a taxa de atendimento da demanda também cresce, impedindo que o estoque de processos entre em uma trajetória 
explosiva" (Castro, 2011, p. 59).

Entretanto, conforme Gomes et al. (2016, 2017), é importante lembrar que a resposta de juízes ao aumento da demanda com mais trabalho pode ser uma resposta temporária, e tende a não se manter ao longo do tempo, o que significa uma diminuição no desempenho no longo prazo. A resposta de juízes e servidores às pressões por produtividade certamente tem um limite. Juízes sobrecarregados estão mais propensos a apresentarem problemas de saúde, tanto emocionais quanto físicos, problemas esses que podem ter impactos consideráveis no desempenho judicial (Gomes et al., 2016).

As conclusões de Castro (2011) e Gomes et al. $(2016,2017)$ podem ser representações da tragédia dos comuns. Essa perspectiva teórica refere-se a problemas nos quais soluções técnicas não são eficazes, mas sim soluções voltadas a mudanças de valores ou ideias de moralidade (Hardin, 1968). Assim, podemos entender o serviço de Justiça como um bem comum. À medida que aumentam os casos judicializados, o acesso a esse bem passa a ser menos eficaz, devido ao aumento do congestionamento de tribunais. Para evitar a restrição ao direito de acesso à Justiça, a primeira resposta tem sido ampliar a quantidade de juízes.

Entretanto, o que os mencionados estudos indicam é que a produtividade individual em determinada unidade tende a diminuir quando novos juízes são contratados, uma vez que isso diminui a pressão individual. Assim, embora a produção da unidade aumente com a chegada de novos juízes, a redução na produtividade individual dos juízes tende a mitigar o ganho produtivo geral.
Além disso, há um limite da capacidade de resposta do Judiciário, o que acarreta um impasse que não pode ser solucionado internamente, mas combinado com outras ações de fora do sistema de Justiça, por exemplo, uma mudança de comportamento da sociedade visando níveis mais baixos de litigiosidade. Vale destacar que a taxa de litigiosidade não foi usada como variável, apenas carga de trabalho e taxa de congestionamento, embora as duas últimas estejam relacionadas diretamente com a litigiosidade.

Embora a demanda judicial e o congestionamento de tribunais sejam temáticas bastante abordadas na literatura, como pode ser visto nos estudos apresentados nesta seção, faltam estudos empíricos a respeito da relação entre a demanda judicial e a força de trabaIho disponível nas unidades de justiça. Em outras palavras, a demanda dos tribunais tem sido pouco considerada em estudos anteriores como um fator relevante para a administração da força de trabalho em geral, e para a alocação de juízes e servidores em específico. O presente estudo busca justamente suprir essa lacuna, questionando de que forma a demanda das justiças estaduais, em termos de congestionamento e carga de trabalho, influencia a alocação de juízes e servidores auxiliares. Os resultados indicam que a distribuição da força de trabalho nas justiças estaduais está em descompasso com a demanda judicial dessas organizações, portanto contrariando a Resolução no 219/2016 do CNJ. Antes de apresentar em detalhe os resultados do estudo, a seção seguinte traz informação a respeito dos métodos utilizados na pesquisa.

\section{MÉTODO}


Os dados analisados neste trabalho são provenientes do relatório anual Justiça em Números, elaborado pelo Conselho Nacional de Justiça (CNJ). Os dados são referentes à primeira instância de todas as 27 justiças estaduais do País, e abrangem um período de oito anos, de 2009 a 2016. Os dados utilizados na pesquisa estão dispostos em formato de painel, formando, assim, uma amostra de 216 observações (27 justiças $\mathrm{x}$ oito anos).

As variáveis utilizadas no estudo consistem em informações a respeito da demanda judicial das justiças estaduais - carga de trabaIho e taxa de congestionamento, e da força de trabalho disponível - quantidade absoluta e quantidade proporcional de juízes e servidores. A definição e operacionalização das variáveis utilizadas no estudo são as seguintes:

a) Carga de trabalho (por juiz): quantidade total de processos novos mais os processos pendentes no ano de referência no tribunal, dividida pela quantidade de juízes que atuam no tribunal.

b) Taxa de congestionamento: quantidade de processos novos na justiça, no ano de referência, mais os processos pendentes, dividida pela quantidade de processos baixados. Representa o percentual de processos pendentes que foi baixado no ano de referência na unidade judicial.

c) Quantidade de juízes: total absoluto de juízes efetivos que atuam na unidade judicial.

d) Quantidade de servidores judiciários: total absoluto de servidores efetivos que atuam em atividades judiciais na unidade judicial, auxiliando diretamente os juízes.

e) Quantidade de servidores administrati- vos: total absoluto de servidores que atuam em atividades administrativas na unidade judicial.

f) Proporção de juízes: quantidade de juízes que atuam na unidade judicial para cada grupo de 100 mil habitantes.

g) Proporção de servidores judiciários: quantidade de servidores que atuam em atividades judiciais na unidade para cada grupo de 100 mil habitantes.

Ressalta-se que a força de trabalho, quando tratada em termos absolutos, refere-se ao número total de juízes e servidores (judiciários e administrativos). Já a força de trabaIho proporcional representa a quantidade de juízes e servidores para cada grupo de 100 mil habitantes. Tratar a força de trabalho de modo proporcional ao número de habitantes permite relativizar a heterogeneidade das justiças estaduais em termos de porte. A variável referente à proporção de servidores administrativos não foi utilizada no estudo em razão de sua pouca relevância teórica.

É importante destacar os diferentes papéis desempenhados por servidores judiciários e administrativos. Os servidores judiciários auxiliam diretamente os juízes nas atividades judiciais, como elaboração e julgamento de litígios, apoio na realização de audiências e consulta de jurisprudência. Os servidores judiciários também realizam atividades administrativas, no entanto suas maiores responsabilidades estão relacionadas com a atividade-fim dos juízes. Entre os servidores judiciários, existem diversos cargos, como analistas e oficiais de justiça. Os servidores administrativos, por sua vez, ficam restritos a trabalhos administrativos menos complexos, geralmente relacionados com a administração das unidades, por exemplo, a ad- 
ministração de recursos, o atendimento ao público e o apoio logístico.

As variáveis utilizadas no estudo certamente não são capazes de abranger toda a complexidade que envolve o funcionamento de tribunais, comarcas e varas das justiças estaduais. Estudos quantitativos, que utilizam variáveis e indicadores objetivos, como é o caso do presente estudo, representam apenas um dos aspectos do funcionamento de tribunais e unidades de Justiça. Embora restrito, esse tipo de estudo pode gerar informações relevantes para os gestores judiciários.

Os dados foram analisados inicialmente por meio de análise estatística descritiva, de modo a identificar os parâmetros de centralidade e dispersão dos dados. Em seguida, foram realizadas análises de correlação linear, técnica estatística que mede a direção e a intensidade da relação entre duas variáveis por meio do cálculo de um coeficiente de correlação. Foi utilizado o coeficiente de
Spearman, tendo em vista que as variáveis não são normalmente distribuídas. Na seção seguinte, são apresentados os resultados das análises.

\section{RESULTADOS}

A Tabela 1 mostra a análise descritiva das variáveis utilizadas no estudo. Em relação à demanda, a carga de trabalho média por juiz é de 4.990 processos, e a taxa de congestionamento média das justiças é 0,69 , o que significa que $69 \%$ dos processos pendentes não foram baixados no ano de referência. $A$ quantidade média de juízes, servidores judiciários e administrativos nas justiças é de, respectivamente, 437, 6.445 e 448 . Já em termos proporcionais, existem, em média, 6,7 juízes e 85,8 servidores judiciários por cada grupo de 100 mil habitantes. As maiores variabilidades, considerando o desvio padrão, estão no total absoluto de servidores judiciários e administrativos, enquanto as menores estão na proporção de juízes e na taxa de congestionamento. 
RELAÇÃO ENTRE DEMANDA JUDICIAL E FORÇA DE TRABALHO NAS JUSTIÇAS ESTADUAIS NO BRASIL

Tabela 1. Estatísticas descritivas das variáveis utilizadas no estudo

\begin{tabular}{lcccc}
\hline \multicolumn{1}{c}{ Variável } & Média & Desvio padrão & Mínimo & Máximo \\
\hline Carga de trabalho por juiz & 4990 & 2686 & 1163 & 17741 \\
Taxa de congestionamento & 0,69 & 0,10 & 0,37 & 0,88 \\
Total de juízes & 437 & 494 & 31 & 2735 \\
Total de servidores judiciários & 6445 & 8439 & 677 & 46291 \\
Total de servidores administrativos & 448 & 855 & 128 & 5542 \\
Proporção de juízes & 6,7 & 2,1 & 3,6 & 13,3 \\
Proporção de servidores judiciários & 85,8 & 45,7 & 30,7 & 258,0 \\
\hline
\end{tabular}

Fonte: Dados da pesquisa

$\mathrm{N}=216$ (27 justiças $\mathrm{x}$ oito anos)

Nota: proporção de juízes e servidores por 100 mil habitantes

A Tabela 2 mostra como as médias das variáveis evoluíram ao longo dos oito anos cobertos pela pesquisa, considerando para isso a diferença entre os valores observados no ano de início da série, 2009, e o ano final, 2016. A média da carga de trabalho por juiz aumentou $27,4 \%$ no período, enquanto a taxa de congestionamento se manteve praticamente a mesma, com leve redução nos primeiros anos, compensada por um leve aumento nos anos finais da série. Enquanto isso, a quantidade absoluta de juízes aumentou $8,7 \%$, enquanto a proporção de juízes por habitantes diminuiu $6 \%$ no período.

Tabela 2. Evolução das variáveis ao longo do período analisado (de 2009 a 2016)

\begin{tabular}{rccccccc}
\hline Ano & $\begin{array}{c}\text { Carga de } \\
\text { trabalho }\end{array}$ & $\begin{array}{c}\text { Taxa de } \\
\text { congestio- } \\
\text {-namento }\end{array}$ & $\begin{array}{c}\text { Total de ju- } \\
\text { ízes }\end{array}$ & $\begin{array}{c}\text { Total de } \\
\text { servidores } \\
\text { judiciários }\end{array}$ & $\begin{array}{c}\text { Total de } \\
\text { servidores } \\
\text { administ. }\end{array}$ & $\begin{array}{c}\text { Proporção } \\
\text { de juízes }\end{array}$ & $\begin{array}{c}\text { Proporção } \\
\text { de serv. } \\
\text { judiciários }\end{array}$ \\
\hline 2009 & 4398 & 0,69 & 11403 & 162345 & 10557 & 187 & 2195 \\
2010 & 4267 & 0,68 & 11774 & 165777 & 14451 & 191 & 2276 \\
2011 & 4575 & 0,69 & 11739 & 169896 & 7760 & 187 & 2330 \\
2012 & 4941 & 0,69 & 11608 & 175467 & 6737 & 183 & 2383 \\
2013 & 5228 & 0,67 & 11843 & 179996 & 6762 & 174 & 2355 \\
2014 & 5218 & 0,68 & 12001 & 181219 & 6471 & 183 & 2511 \\
2015 & 5695 & 0,70 & 11845 & 180067 & 12109 & 168 & 2352 \\
2016 & 5600 & 0,70 & 12392 & 178971 & 10017 & 175 & 2283 \\
Variação & $\mathbf{2 7 , 4} \%$ & $\mathbf{1 , 5} \%$ & $\mathbf{8 , 7} \%$ & $\mathbf{1 0 , 3} \%$ & $\mathbf{- 5 , 1} \%$ & $\mathbf{- 6 , 0} \%$ & $\mathbf{4 , 1} \%$ \\
\hline
\end{tabular}

Fonte: Dados da pesquisa

$\mathrm{N}=27$ justiças estaduais

Nota 1: proporção de juízes e de servidores por 100 mil habitantes

Nota 2: a variação em termos percentuais (última linha) considerou a diferença entre 2009 e 2016 
Para compreender como as variáveis estão relacionadas entre si, foram realizados testes de correlação linear. A Tabela 3 mostra os resultados obtidos. Observa-se que tanto a carga de trabalho quanto a taxa de congestionamento estão correlacionadas positivamente com a força de trabalho absoluta - juízes e servidores (judiciários e administrativos). A correlação mais forte ocorre entre a carga de trabalho e a quantidade absoluta de juízes. Isso significa que as justiças que contam com mais juízes em termos absolutos, portanto as maiores justiças, são as mais demandadas, e também as mais con- gestionadas.

Por outro lado, quando considerada a força de trabalho proporcional à quantidade de habitantes os resultados são muito diferentes. Como pode ser visto na Tabela 3, a proporção de juízes e a proporção de servidores está negativamente correlacionada com a carga de trabalho e com a taxa de congestionamento. Assim, quanto maior a carga de trabalho e a taxa de congestionamento observados, menor a proporção de juízes e de servidores disponíveis na justiça.

Tabela 3. Resultado da análise de correlação linear

\begin{tabular}{|c|c|c|c|c|c|c|c|}
\hline Variáveis & $\mathbf{T J}$ & TSJ & TSA & PJ & PS & CT & TC \\
\hline $\begin{array}{l}\text { Total de } \\
\text { juízes (TJ) }\end{array}$ & 1 & & & & & & \\
\hline $\begin{array}{l}\text { Total de } \\
\text { servidores judiciários (TSJ) }\end{array}$ &, $948^{\star *}$ & 1 & & & & & \\
\hline $\begin{array}{l}\text { Total de } \\
\text { servidores administrativos (TSA) }\end{array}$ &, $705^{\star *}$ &, $737^{\star *}$ & 1 & & & & \\
\hline $\begin{array}{l}\text { Proporção } \\
\text { de juízes (PJ) }\end{array}$ &,$- 348^{* *}$ &,- 292 & ,032 & 1 & & & \\
\hline $\begin{array}{l}\text { Proporção de } \\
\text { servidores judiciários (PSJ) }\end{array}$ &,$- 254^{\star *}$ &,- 073 &,$- 167^{*}$ &, $776^{* *}$ & 1 & & \\
\hline $\begin{array}{l}\text { Carga de } \\
\text { trabalho }(\mathrm{CT})\end{array}$ &, $706^{* *}$ &, $594^{* *}$ &, $653^{* *}$ &,$- 406^{* *}$ &,$- 201^{* *}$ & 1 & \\
\hline $\begin{array}{l}\text { Taxa de } \\
\text { congestionamento (TC) }\end{array}$ &, $370^{* *}$ &, $296^{* *}$ &, $172^{* *}$ &,$- 514^{* *}$ &,$- 463^{\star *}$ &, $528^{\star *}$ & 1 \\
\hline
\end{tabular}

Fonte: Dados da pesquisa.

$\mathrm{N}=216$

${ }^{*} p<, 05 ;{ }^{* *} p<, 01$.

Coeficiente de correlação linear de Spearman 
Esse resultado significa que as justiças mais sobrecarregadas, ou seja, aquelas que contam com maior carga de trabalho e maior taxa de congestionamento, são aquelas que apresentam menor proporção de juízes e servidores. Assim, as justiças estaduais, embora apresentem uma força de trabalho absoluta maior, proporcionalmente possuem uma força de trabalho menor do que outras justiças menos congestionadas. Isso indica que a alocação de pessoas não segue critérios atrelados à demanda das justiças. Resultado parecido foi encontrado por Gomes e Freitas (2017) na Justiça Federal.

As correlações negativas observadas entre a força de trabalho absoluta e a força de trabalho proporcional reforçam os resultados apresentados acima. Uma maior quantidade de juízes e servidores em um tribunal não deve ser considerada isoladamente como uma vantagem para lidar com a demanda judicial. Deve-se verificar se essa força de trabalho é condizente com o contexto de atuação do tribunal, o que envolve, entre outras coisas, o potencial de demanda do tribunal em razão do tamanho da população e da litigiosidade. Assim, conforme Aragão (1997), Castro (2011), Yeung e Azevedo (2012), Fochezatto (2013) e Gomes e Freitas (2017), apenas aumentar a força de trabalho não necessariamente resultará em uma maior eficiência da unidade judicial, e, da mesma forma, aumentar a força de trabalho, por si só, não é capaz de diminuir o congestionamento das justiças. Uma discussão mais aprofundada a respeito de produtividade, eficiência e outras variáveis relacionadas com desempenho judicial pode ser encontrada em Gomes e Guimaraes (2013).

Sob a perspectiva da tragédia dos comuns, à medida que a população aumenta, os bens comuns passam a ser restringidos (Hardin, 1968). Nesse sentido, observa-se um efeito perverso relacionado à ampliação da quantidade de juízes nas justiças estaduais em contraste com o aumento da população e de sua litigiosidade. Ao perceber os serviços de justiça como um bem comum, à medida que a população aumenta, mantendo ou ampliando seus níveis de litigiosidade, passam a ser necessários cada vez mais juízes para suprir o aumento da demanda.

Possíveis soluções para esse efeito poderiam atacar tanto no lado da oferta quanto no lado da demanda dos serviços de justiça no País. Em relação à oferta, uma possível solução seria o seguimento estrito da Resolução no 219/2016 do CNJ, de modo que o aumento da quantidade de juízes seria o fator determinante para que a força de trabalho fosse aumentada. No que se refere à demanda, uma medida que poderia ajudar seria a ampliação e o fortalecimento da estratégia de utilização dos mecanismos de alternativos de resolução de litígios nas unidades, como a conciliação e a mediação judicial.

\section{CONCLUSÕES}

O presente estudo teve como objetivo descrever a relação entre a demanda e a força de trabalho disponível nas justiças estaduais no Brasil, considerando o período de 2009 a 2016. Os resultados indicam que, enquanto a força de trabalho absoluta está positivamente correlacionada com a carga de trabaIho e com a taxa de congestionamento das justiças, a força de trabalho proporcional está correlacionada negativamente com essas mesmas variáveis. Esse resultado ajuda 
a explicar por que, apesar de contarem com uma quantidade maior de pessoal, as maiores justiças são tradicionalmente as mais congestionadas.

Além disso, os resultados indicam dissonância entre a evolução da carga de trabalho e do congestionamento em relação à evolução da força de trabalho. Com efeito, verifica-se a necessidade de definição de critérios objetivos para a alocação de recursos de pessoal no Judiciário em geral e na Justiça Estadual em particular. Vale ressaltar a pluralidade de contextos socioeconômicos existente nos diversos estados brasileiros. As justiças estaduais possuem capacidades específicas de captação de recursos e autonomia na alocação de pessoal. Desse modo, é possível a existência de racionalidades distintas na criação e na alocação de cargos na Justiça Estadual.

Os resultados deste estudo são importantes para a administração da Justiça no Brasil, uma vez que apontam possíveis falhas nas políticas de alocação de pessoal na primeira instância das justiças estaduais. Essas políticas poderiam ser revistas com bases neste e em outros resultados de estudos empíricos, de modo que os gestores possam buscar medidas capazes de equilibrar a distribuição de pessoal conforme a demanda judicial. No entanto, apesar de os resultados serem sugestivos nesse sentido, é necessário ressaltar que muitas das decisões a respeito da alocação de pessoal nas varas de Justiça e nos tribunais, em especial a alocação de juízes, não estão amparadas em critérios técnicos. Isso porque os critérios de alocação de pessoal, especialmente de juízes, dependem de uma série de fatores, como antiguidade, evolução na car- reira, produtividade individual e preferências pessoais.

Essas recomendações são especialmente válidas para os gestores do CNJ, responsáveis por pensarem estrategicamente o Judiciário brasileiro, incluindo a Justiça Estadual. Isso porque, no Brasil, conforme Resolução no 67 de 2009, cabe ao CNJ a função, entre outras, de elaborar relatórios sobre processos, políticas de otimização da mão de obra disponível e avaliação de desempenho de juízes e tribunais. O CNJ também é responsável por gerar propostas de medidas e indicadores capazes de retratar a situação dos tribunais, bem como diagnósticos, avaliações e projetos de gestão dos diversos ramos do Poder Judiciário, visando a modernização, desburocratização e eficiência dos tribunais e das demais unidades justiça (CNJ, 2009).

Conforme destacado ao longo do texto, o CNJ não tem ficado alheio a essa discussão. Editou, em 2016, a Resolução no 219, dispondo sobre a distribuição de cargos de servidores e de cargos em comissão nos órgãos do Poder Judiciário de primeiro e segundo graus. Os critérios adotados para tal distribuição envolvem a taxa de congestionamento, índice de produtividade de servidores, bem como a quantidade de processos em tramitação. Destaca-se também, nesse instrumento, o estabelecimento da realização de mutirões como medida voltada a impedir a elevação acentuada da taxa de congestionamento. No que se refere à distribuição dos cargos de juiz, a própria Constituição Federal (1988) estabelece que deva ser proporcional à demanda judicial e à população.

Por fim, seria importante que novos estudos investigassem a relação entre demanda judi- 
cial e força de trabalho nos demais segmentos do Judiciário brasileiro. Importante também que esse fenômeno fosse investigado qualitativamente, por meio de entrevistas em profundidade com gestores das justiças, juízes e servidores. Além disso, recomenda-se que sejam realizados estudos comparativos entre as justiças brasileiras e de outros países. Esse tipo de estudo poderia gerar novas propostas para enfrentar o congestionamento e a morosidade judicial no Brasil, uma vez que soluções, boas práticas e inovações verificadas em judiciários de outros países poderiam ser adaptadas e utilizadas no Brasil.

\section{REFERÊNCIAS}

Aragão, C. V. (1997). Fatores agilizadores e restritivos à atuação da Justiça do Trabalho: Um estudo exploratório. RAP-Revista de Administração Pública, 31(4), 183-215.

Banco Mundial. (1999, July). Court performance around the world: A comparative perspective. Technical Paper n. 430.

Beenstock, M., \& Haitovsky, Y. (2004). Does the appointment of judges increase the output of the judiciary? International Review of Law and Economics, 24(3), 351-369. doi:10.1016/j.irle.2004.10.006

Capellari, E. (2001). A crise do Poder Judiciário no contexto da modernidade: $A$ necessidade de uma definição conceitual. Revista de Informação Legislativa, 38(152), 135149.

Castro, A. S. (2011). Indicadores básicos e desempenho da Justiça Estadual de primeiro grau no Brasil. Brasília, DF: Ipea.
Conselho Nacional de Justiça. (2009). Regimento interno. Recuperado de http://www. cnj.jus.br/publicacoes/regimento-interno-e-regulamentos

Conselho Nacional de Justiça. (2015). Metas nacionais para 2016. Recuperado de http://www.cnj.jus.br/files/conteudo/arquivo/2016/03/f2ed11abc

Conselho Nacional de Justiça. (2017). Justiça em números 2017: Ano-base 2016. Recuperado de http://www.cnj.jus.br/files/ conteudo/arquivo/2017/12/b60a659e5d5cb79337945c1dd137496c.pdf

Constituição Federal de 1988. (1988). Promulgada em 5 de outubro de 1988. Brasília, DF. Recuperado de http://www.planalto.gov. br/ccivil_03/constituicao/constituição.htm, acesso em 3.2.2019.

Dimitrova-Grajzl, V., Grajzl, P., Sustersic, J., \& Zajc, K. (2010). Court output, judicial staffing, and the demand for court services: Evidence from Slovenian courts of first instance. Annual Conference on Empirical Legal Studies, 5. Yale Law School, New Haven, Connecticut.

Filgueiras, F., \& Marona, M. (2012). A corrupção, o judiciário e a cultura política no Brasil democrático, em BIASON, Rita de Cássia (Org.). Temas de corrupção política. São Paulo, SP: Balão Editorial.

Fochezatto, Adelar. Gestão Pública no Poder Judiciário: análise da eficiência relativa dos tribunais estaduais usando o método DEA. Economic Analysis of Law Review, v. 4, p. 377-392, 2013. 
Gomes, A., Alves, S. T., \& Silva, J. T. (2018). Effects of investment in information and communication technologies on productivity of courts in Brazil. Government Information Quarterly, 35(3), 480-490. doi:10.1016/j. giq.2018.06.002

Gomes, A., \& Freitas, M. E. (2017). Correlação entre demanda, quantidade de juízes e desempenho judicial em varas da Justiça Federal no Brasil. Revista Direito GV, 13(2), 567-585. doi:10.1590/2317-6172201722

Gomes, A., \& Guimaraes, T. (2013). Desempenho no Judiciário: Conceituação, estado da arte e agenda de pesquisa. RAP-Revista de Administração Pública, 47(2), 379-402. doi:10.1590/S0034-76122013000200005

Gomes, A. O., Guimaraes, T. A., \& Akutsu, L. (2016). The relationship between judicial staff and court performance: Evidence from Brazilian state courts. International Journal for Court Administration, 8(1), 12-19. doi:10.18352/ijca.214

Gomes, A. O., Guimaraes, T. A., \& Akutsu, L. (2017). Court caseload management: The role of judges and administrative assistants.
RAC-Revista de Administração Contemporânea, 21(5), 648-665. doi:10.1590/1982-7849rac2017160179

Hardin, G. (1968). The tragedy of the commons. Science, 162(3859), 1243-1248. doi:10.1126/science.162.3859.1243

Pastor, S. (2003). Eficiencia y eficacia de la justicia. Papeles de Economía Española, 95, 272-305.

Souza, M. C. S., \& Schwengber, S. B. (2005). Efficiency estimates for judicial services in Brazil: Nonparametric FDH and the expected ordem-m efficiency scores for Rio Grande do Sul Courts. Encontro da ANPEC, Natal, RN, 33.

Vianna, L. W. (2013). A judicialização da política, em AVRITZER, Leonardo et al. (orgs.). Dimensões políticas da justiça. Rio de Janeiro, RJ: Civilização Brasileira.

Yeung, L., \& Azevedo, P. (2012). Além dos "achismos" e das evidências anedóticas: Medindo a eficiência dos tribunais brasileiros. Economia Aplicada, 16(4), 643-663. doi:10.1590/S1413-80502012000400005 